\title{
Intensity of climacteric symptoms in postmenopausal women
}

\author{
Intensidade da sintomatologia climatérica em mulheres pós-menopausa
}

Thaiene Rodrigues dos Santos ${ }^{1}$, Sandra Valéria Martins Pereira ${ }^{1}$, Renato Lopes Santos ${ }^{1}$

Objective: to evaluate the characteristics and intensity of climacteric symptoms in postmenopausal women. Methods: a cross-sectional, descriptive study with systematic sampling, consisting of 247 women in post menopause, who answered the Questionnaire of Women's Health. To evaluate the intensity of climacteric symptoms the Menopausal Index of Blatt and Kupperman was used. Statistical analysis was performed using the Statistical Package for Social Sciences software version 17, a significance level of 5\% and 95\% confidence intervals for all analyzes were adopted. Results: $36.8 \%$ of women had mild climacteric symptoms, 56.3\% moderate and $6.9 \%$ severe. In descending order hot flushes, irritability and sleep disorders reached the highest intensity ratios. Conclusion: the Menopausal index of Blatt and Kupperman (25.34) showed symptoms of moderate intensity. Hot flushes showed to be the symptom of highest intensity of discomfort.

Descriptors: Climacteric; Postmenopause; Signs and Symptoms.

Objetivo: avaliar as características e a intensidade da sintomatologia climatérica em mulheres pós-menopausa. Métodos: estudo transversal, descritivo. Amostra sistemática, composta de 247 mulheres em pós-menopausa, que responderam ao Questionário de Saúde da Mulher. Para avaliação da intensidade da sintomatologia climatérica, utilizou-se o Índice Menopausal de Blatt e Kupperman. A análise estatística foi realizada no software Statistical Package for the Social Sciences versão 17. Adotou-se nível de significância de 5\% e intervalo de confiança 95\% para todas as análises. Resultados: 36,8\% das mulheres apresentaram sintomatologia climatérica leve, 56,3\% moderada e 6,9\% severa. Em ordem decrescente fogachos, irritabilidade e distúrbios do sono alcançaram os maiores índices de intensidade. Conclusão: o índice global Menopausal de Blatt e Kupperman $(25,34)$ indicou sintomatologia de intensidade moderada. Fogacho mostrou-se o sintoma de maior intensidade de desconforto. Descritores: Climatério; Pós-menopausa; Sinais e Sintomas.

\footnotetext{
${ }^{1}$ Centro Universitário de Anápolis. Anápolis, GO, Brazil. 


\section{Introduction}

The increase in life expectancy in all regions of the world except in sub-Saharan Africa, implies in the increase of female longevity and time of life after menopause. The estimate for 2030 is that about 1200 million women will be in menopause transition ${ }^{(1)}$.

The climacteric comprises the passing of the female reproductive stage to the non-reproductive one, before and after the last period, usually between 40-65 years of age. In this phase multidimensional clinical manifestations are perceived subjectively by women from different parts of the world ${ }^{(1-2)}$.

In most cases, vasomotor symptoms are the first to affect women. There are reports that hot flushes and night sweats cause intense discomfort. In the medium and long term range, neuropsychiatric, urinary, sleep and sexuality disorders, if not controlled, can jeopardize the quality of life ${ }^{(3)}$.

In Latin America, in general, menopause occurs between 43.8 to 53 years of age, which is below to the one found in developed countries. The effects of menopause for women in this region have been of special concern to international health organizations due to the accelerated process of population aging and social vulnerability experienced there ${ }^{(2)}$.

In Brazil, the age structure of the last decade shows the same tendency to the intense population aging registered in other countries of Latin America. The estimated life expectancy is 78.5 years, with emphasis on the increase of the 45-year-old segment or more, as well as the female population ${ }^{(4)}$. Thus, there is expected gradual increase in the demand for health services by women with problems related to menopause $^{(5)}$.

In this context, due to the disparity in the distribution of health services in the country, many women, due to lack of knowledge, attribute, solely and exclusively, to menopause the burden of symptoms, making this period the most feared stage of their lives. One has to note that these symptoms may be associated to clinical co-morbidities, as well as to demographic, socioeconomic, ethnic and cultural factors and the distortion of their real causes hinders the ability of coping with those and consequent selfcare by part of that population ${ }^{(6)}$.

Facing the above problems, it is worth recalling that the approach of women in menopausal condition follows the global consensus, which recommends, in any field of health sector, overcoming the mechanistic and reductionist issues through a holistic approach. The new integrative and not exclusionary paradigm is guided by the concept of health promotion, focusing on raising the quality of life. However, in Brazil, similar to Latin America, this process has faced many obstacles, making its implementation a challenge to managers and health professionals ${ }^{(5)}$.

The evaluation of the intensity of symptoms, related factors and the multiple effects of Climacteric Syndrome in health and quality of life of population groups of interest, has been the objective of scientific studies worldwide $\mathrm{e}^{(3,5-10)}$.

This study aimed at evaluating the characteristics and intensity of climacteric symptoms in postmenopausal women.

\section{Methods}

It is a cross-sectional study. The sampling consisted of climacteric women in the postmenopausal period, 45-60 years old, living in the county of Anapolis, GO. This county is located in the central highlands of Brazil, with an area of $917.011 \mathrm{~km} 2$ and urbanization of $97.3 \%$. The female population in 2010 was 177,410 , of which 28,786 were in the age group of 45-60 years, considered at risk of menopause ${ }^{(11)}$.

Facing the above information, considering $16.2 \%$ of the proportion in the population, the maximum error desired of 5\% and significance level of $5.0 \%$, a probability sample of 247 women over 
$20.0 \%$ for possible losses was calculated.

There was a research with high flow of women in the age group of interest was made in the following venues: basic health units, associations, street markets, squares and public parks and malls.

The time measured in months of the last menstrual period based the classification of menopausal status. It was considered menopausal women in permanent cessation state of menstruation for at least 12 consecutive months of amenorrhea without obvious pathological or physiological cause ${ }^{(1)}$.

For inclusion in the study, the following criteria were used: women with 45-60 years of age who reported being in post-menopausal period and the ones who were alone at the time of data collection to avoid embarrassment and information bias.

A systematic sampling was adopted, and the street markets, squares, parks and malls became a starting point for selection of the sample the first woman included in the study, and from then on the interval of 1:3 was adopted. At first, In the basic health units and associations, the researchers made a list of women who were eligible for the study from medical records or their own records. In each list of 50 women, the first woman was chosen at random and from then on the interval 1: 3 was adopted.

Data collection occurred in September 2015, when 279 women were approached and from those 247 were interviewed, with a proportion of $11.0 \%$ non-response. The participants answered a written interview by data collection instrument adapted from the Women's Health Questionnaire (WHQ), Portuguese version, which was supplemented with questions to research socioeconomic, cultural and gynecological factors. In addition, the menopausal index of Blatt and Kupperman (MIBK) was attached to the instrument for analysis and classification of the intensity of climacteric symptoms.

The Women's Health Questionnaire is an instrument for the evaluation of physical and mental symptoms experienced by women during the climacteric period. In its original form, it consists of
37 questions, divided into nine areas, which evaluate: depressed mood, somatic symptoms, cognitive impairment, vasomotor symptoms, anxiety, sexual function, sleep problems, menstrual problems and self-esteem. It offers a structured format, with options of response in the scales of Likert of four-points: yes, definitely yes, sometimes, not much and no in all $\operatorname{areas}^{(10)}$.

The MIBK allows the analysis and classification of the intensity of climacteric symptoms in menopausal obtained by the evaluation rating scales. It includes 11 symptoms or complaints: vasomotor, paraesthesia, insomnia, nervousness, melancholia, vertigo, fatigue, arthralgia/myalgia, headache, palpitations and tingling, classified in mild, moderate and severe, corresponding to the numerical values 1, 2 and 3, respectively. Subsequently different weights should be assigned to the symptoms: vasomotor, weight 4 , paresthesia, sleep disorders and irritability, weight 2 and the others weight 1 . In the end, the overall index is obtained by summing the scores achieved in each symptom, which leads to the following classification: mild intensity $\leq 19$, moderate intensity $\geq 20$ and $\leq 35$ and severe intensity> 35. WHQ highest score in the domains corresponds to the highest score in this index ${ }^{(12)}$.

Fellows and assistants of properly trained researchers applied the questionnaires presented above.

The descriptive statistical analysis used the Statistical Package for the Social Sciences version $17^{\circledR}$. significance level adopted was 5.0\% and $95.0 \%$ confidence interval for the entire analysis. Demographic, socioeconomic, cultural and gynecological factors were dichotomized and coded in 0 and 1 for identification of absolute and percentage distributions. The average and standard deviation for BKMI scores were found.

The study complied with the formal requirements contained in the national and international standards of regulatory research involving human subjects. 


\section{Results}

The age of participants ranged from 45-60 years on average 52 years ( \pm 5.07 ). According to their information, the age of occurrence of menopause ranged from 28-59 years on average $47.43( \pm 4.70)$. All were postmenopausal women, the amenorrhea time ranged from 1-32 years on average of 5 years. More than $70.0 \%$ had a husband or stable mate, the rest were single or widowed, $80.2 \%$ reported they were sexually active.

The demographic and socioeconomic profile shows low levels of education, employment and household income, $48.2 \%$ less than eight years of study, 37.7\% between 8 and 12 years, 9.7\% over 12 years and $4.5 \%$ reported to be illiterate, $58.7 \%$ were housewives, $59.5 \%$ reported family income of 1-5 minimum wages, $24.7 \%$ less than a minimum wages and $15.8 \%$ more than six.

Tables 1 and 2 show the distribution of climacteric symptoms according to the intensity and MIBK in postmenopausal women in the county of the research.

It can be seen from Table 1 that the frequency of symptoms found in descending order was: irritability (92.0\%), depression (80.2\%), hot flushes (79.8\%), arthralgia / myalgia (77.7\%) fatigue (73.3\%), sleep disorders (70.9\%), headache (65.9\%), numbness or tingling (64.0\%), dizziness and / or tinnitus (62.4\%) and palpitations (55.9\%). It is observed that palpitation appeared less frequently. In contrast, irritability had the highest prevalence and was considered as severe intensity (31.6\%) and moderate intensity $(48.2 \%)$ were considered by the majority. Depression, reported by $80.2 \%$ of women had the second most frequently occurrence. However, only $6.9 \%$ considered it with severe intensity. Myalgia was highlighted as the symptom with the highest proportion of severe intensity (39.3\%).
Table 1 - Distribution of postmenopausal women with 40-65 years of age, the frequency and intensity of climacteric symptoms and to the Menopausal Index of Blatt and Kupperman

\begin{tabular}{lcccc}
\hline \multirow{2}{*}{ Climacteric symptoms } & Absent & Mild & Moderate & Severe \\
\cline { 2 - 5 } & $\mathbf{n}(\%)$ & $\mathbf{n}(\%)$ & $\mathbf{n}(\%)$ & $\mathbf{n ( \% )}$ \\
\hline Irritability & $20(8.10)$ & $30(12.1)$ & $119(48.2)$ & $78(31.6)$ \\
Depression & $49(19.8)$ & $87(35.2)$ & $94(38.1)$ & $17(6.90)$ \\
Hot flushes & $50(20.2)$ & $41(16.6)$ & $67(27.1)$ & $89(36.0)$ \\
Arthralgia/myalgia & $55(22.3)$ & $28(11.3)$ & $67(27.1)$ & $97(39.3)$ \\
Tiredness/fatigue & $66(26.7)$ & $34(13.8)$ & $80(32.4)$ & $67(27.1)$ \\
Sleep disorders & $72(29.1)$ & $39(15.8)$ & $60(24.3)$ & $76(30.8)$ \\
Headache & $84(34.1)$ & $39(15.9)$ & $74(30.1)$ & $49(19.9)$ \\
Paresthesia/tingling & $89(36.0)$ & $27(10.9)$ & $78(31.6)$ & $53(21.5)$ \\
Vertigo/dizziness/tinnitus & $93(37.6)$ & $40(16.2)$ & $81(32.8)$ & $33(13.4)$ \\
Palpitations & $109(44.1)$ & $55(22.3)$ & $63(25.5)$ & $20(8.10)$ \\
MIBK ${ }^{\dagger}$ & - & $91(36.8)$ & $139(56.3)$ & $17(6.90)$ \\
\hline${ }^{\dagger}$ Menopausal Index of Blatt and Kupperman: $\leq 19=$ mild, moderate and $20 \leq 35$ \\
$=>35=$ severe intensity
\end{tabular}

Tables 1 and 2 shows that according to the MIBK, there was a predominance of climacteric symptoms of moderate intensity (56.3\%), followed by mild symptoms of $36.8 \%$ and $6.9 \%$ severe symptoms. The hot flushes appear as a symptom of more severe intensity. The MIBK (25.34) reveals moderate symptoms.

Table 2 - Average Distribution of intensity of climacteric symptoms in postmenopausal women according to the Menopausal Index of Blatt and Kupperman

\begin{tabular}{lc}
\hline Symptoms & Average $\mathbf{M I B K}^{\dagger}$ \\
\hline Hot flushes & $7.16( \pm 4.50)$ \\
Irritability & $3.93( \pm 1.66)$ \\
Insomnia & $3.13( \pm 2.41)$ \\
Somatic disorders & \\
Paresthesia & $2.78( \pm 2.37)$ \\
Fatigue & $1.60( \pm 1.15)$ \\
Headache & $1.37( \pm 1.16)$ \\
Depression & $1.37( \pm 0.86)$ \\
Arthralgia/myalgia & $1.83( \pm 1.17)$ \\
Dizziness $/$ tinnitus & $1.22( \pm 1.09)$ \\
Palpitations & $0.98( \pm 1.01)$ \\
Average BKMI ${ }^{\dagger}$ sample scores & $25.34( \pm 10.0)$ \\
\hline †enopausal Index Blatt and Kupperman: $\leq 19=$ mild, moderate and $20 \leq 35$ \\
$=>35$ = severe intensity
\end{tabular}




\section{Discussion}

Latin American women experience menopause earlier than the ones in developed countries ${ }^{(2)}$. It is observed the same pattern in Annapolis, where menopause occurred with an average of five years before the average age found in Europe and North America $^{(3)}$ and a little before Latin America ${ }^{(2)}$. This information is relevant by scientific evidence that early menopause increases the risk of osteoporosis, cardiovascular disease and discomfort due mainly to hot flushes and night sweats, pain and emotional limitations ${ }^{(2-3)}$.

Another aggravating factor in the condition of climacteric women in Annapolis is the social vulnerability expressed by low levels of education, employment and income. Unfavorable social framework similar to that found in Latin America ${ }^{(2)}$. It is important to consider that the lack of access to health services and programs exacerbates the situation, making the enhancement of services of health care important, aiming at better levels of quality of life for this population.

Somatic symptoms were found among women in the sampling, such as fatigue, headache, dizziness and tinnitus, paresthesia. Similar results were found for all of these symptoms in women from Maceio, $\mathrm{AL}$, Brazil $^{(13)}$.

Hot flushes were found in $79.8 \%$ of women, $36.0 \%$ considered them of severe intensity. This symptom achieved the highest intensity score MIBK. Hot flushes are sudden heat waves, which cause severe discomfort, along with night sweats are the most common complaints from climacteric women. Vasomotor symptoms cause severe discomfort in many women during the menopause transition, with a negative impact on quality of life and ability to work ${ }^{(3)}$.

Similar results were found in climacteric women in counties of the Northeastern region of the country ${ }^{(13-14)}$. In Latin American countries, the quality of life in postmenopausal women showed proportionally inverse association with the intensity of vasomotor symptoms ${ }^{(2)}$.

The prevalence and degree of intensity of hot flushes in menopausal women may be related to menopausal status and age $\mathrm{a}^{(9)}$. Women of a metropolitan region of southeastern Brazil showed greater intensity of symptoms before and after two years of menopause, so the more advanced the age, the less severe the symptoms were ${ }^{(8)}$.

Most women (92.0\%) complained of irritability, only $12.0 \%$ considered mild and other moderate or severe intensity. The MIBK average found for this symptom was the second highest, behind hot flushes. Similar prevalences were found in studies with climacteric women living in other parts of the country ${ }^{(13-15)}$. In the county of Passo Fundo in southern Brazil, irritability, low education level and memory loss were considered risk factors for mild psychiatric disorders in women in menopause transition who underwent an outpatient screening followed by home care $^{(16)}$

Mild depression was present in $80.2 \%$ of women. Episodes of depression may be associated to hormonal fluctuations, characteristic of perimenopause and often other extrinsic factors such as socioeconomic conditions, changes in the pace of life and/or family structure ${ }^{(3)}$.

During the menopause transition, vasomotor and psychological symptoms can cause significant discomfort for most women, having an impact on their quality of life and ability to work. Perimenopause has been described as a gateway to vulnerability to depression. However, there is debate about the extent that the mood disorder and depression are related to menopause. In clinical practice, there are many women who report to be depressed due to menopause, and many of them receive medical diagnosis of depression ${ }^{(3,16)}$.

A study made in a metropolitan area of the southeast found an association between the presence of anxiety and/or depression and the selfperception of this condition of health as bad or worse and the highest intensity of climacteric symptoms ${ }^{(8)}$. 
Systematic revision of the literature found an association between vasomotor symptoms and depressive symptoms ${ }^{(17)}$.

Fatigue was reported as a complaint by $73.3 \%$ of women. It was observed that this symptom appeared in greater proportion in the county of Passo Fundo where women had complaints of fatigue at all stages of menopause transition ${ }^{(16)}$. A multicentered study in the United States of America has found an association between early menopause and the occurrence of fatigue and lack of energy ${ }^{(3)}$.

Myalgia was found in $77.7 \%$ of women, $39.3 \%$ presented severe intensity and $27.1 \%$ moderate. Similar results were found in household survey in the county of Maceió, Alagoas, with climacteric women in the same age group, where $81 \%$ of them reported myalgia and arthralgia, $43.5 \%$ of severe intensity and $33.0 \%$ moderate ${ }^{(13)}$. In the state of Acre, $74.8 \%$ of postmenopausal women had this symptom ${ }^{(15)}$.

Sleep disorders were referred by $71.0 \%$ of women, more $55.0 \%$ presented moderate or severe intensity of insomnia, the MIBK average was the third highest of the identified symptoms. It is interesting to observe that hot flushes are considered as a common cause of insomnia during menopause. Night Heat waves may be responsible for the increase of episodes of nocturnal awakening and the reduction of sleep ${ }^{(18)}$.

Palpitations were found in $55.9 \%$ of women in Anapolis, where only $8.1 \%$ presented severe intensity. Similar frequency of this symptom was present in climacteric women assisted in a Health Family Unit of Recife, Pernambuco ${ }^{(14)}$.

Over $80.0 \%$ of women reported to have active sex life. It is interesting to consider that the age at which women experience the postmenopause period coincides with a reduction in professional duties and household chores, providing more time for sexual activities. In a study of the population developed in a Basic Health Unit in Natal, Rio Grande do Norte, a proportionally inverse relationship was found, with a level of statistical significance between climacteric symptoms and sexual function. Women with climacteric symptoms showed greater chance of sexual dysfunction $^{(19)}$.

In the same study, symptoms of psychological domain, such as depressed mood, irritability, anxiety, and physical and mental exhaustion presented statistically significant association with sexual dysfunction $^{(19)}$. However, it is important to take into account that other biopsychosocial factors may influence sexual function.

According to the MIBK scores $56.3 \%$ of women in Annapolis had moderate symptoms. Similar data were found in a study of women in post-menopausal period in Rio Grande do Norte ${ }^{(20)}$. A study conducted in China, with women with similar characteristics also predominated symptoms of moderate intensity ${ }^{(12)}$.

This study identified the characteristics and distribution of climacteric symptoms, and also to know their intensity among women in post menopause period in the county of research. This information is important to estimate the impact of menopause on the welfare and quality of life of this population.

However, considering the subjectivity that the menopause transition is experienced by the woman, a more precise interpretation should consider the importance of the influence of socioeconomic, ethnic and cultural factors in symptoms.

However, this study showed the characteristic limitations of the cross-work design, not allowing the elucidation of factors related to the intensity of climacteric symptoms. Thus, the results found provoke deeper questioning on the event, pointing to the need to develop studies with designs that allow the inference of these factors.

\section{Conclusion}

The results of this study show that postmenopausal women showed climacteric symptoms predominantly of moderate intensity. The proportion of severe symptoms intensity was low. Hot flushes, irritability and sleep disorders had higher intensity rates in relation to somatic symptoms. 
It is known that the higher the MIBK is, the more intense the climacteric symptoms and their negative influence on quality of life will be. Therefore, it is concluded that the global intensity of symptoms points to moderate disturbance of quality of life, highlighting hot flushes as the most intense and uncomfortable symptoms.

Knowing the intensity and climacteric symptoms characteristic in the county of research may guide the selection of efficient strategies and actions aiming at a whole approach, clarifying doubts and motivation of the population of interest to health promotion and raising the quality of life.

\section{Acknowledgement}

The Conselho Nacional de Desenvolvimento Científico e Tecnológico for the financial support to the research. Process No. 144963/2014-0.

\section{Collaborations}

Santos TR contributed in the writing of the article and relevant critical revision of the intellectual content. Pereira SVM contributed to the conception, design and final approval of the version to be published. Santos RL contributed to the analysis and interpretation of data.

\section{References}

1. World Health Organization. Research on the menopause in the 1990s: report of a WHO scientific group. WHO technical report series. [Internet]. Geneva: World Health Organization; 1996 [cited 2015 Oct 11]. Available from: http:// apps.who.int/iris/bitstream/10665/41841/1/ WHO_TRS_866.pdf

2. Palacios S, Henderson VW, Siseles N, Tan D, Villaseca P. Age of menopause and impact of climacteric symptoms by geographical region. Climacteric. 2010; 13(5):419-28.
3. Hess R, Thurston RC, Hays RD, Chang CC, Dillon $\mathrm{SN}$, Ness RB, et al. The impact of menopause on health-related quality of life: results from the stride longitudinal study. Qual Life Res On line [Internet]. 2012 [cited 2014 Nov 10]; 21(3):53544. Available from: http://doi.org/10.1007/ s11136-011-9959-7

4. Instituto Brasileiro de Geografia e Estatística. Ministério do Planejamento, Orçamento e Gestão. Síntese de indicadores sociais: uma análise das condições de vida da população brasileira - 2014. Rio de Janeiro: IBGE; 2014.

5. Lorenzi DRS, Catan LB, Moreira K, Ártico GR. Assistência à mulher climatérica: novos paradigmas. Rev Bras Enferm. 2009; 62(2):28793.

6. Valença CN, Germano RM. Concepções de mulheres sobre menopausa e climatério. Rev Rene. 2012; 11(1):161-71.

7. De Lorenzi DRS, Catan LB, Cusin T, Felini R, Bassani F, Arpini AC. Caracterização da qualidade de vida segundo o estado menopausal entre mulheres da Região Sul do Brasil. Rev Bras Saúde Mater Infant. 2009; 9(4):459-66.

8. Lui Filho JF, Baccaro LFC, Fernandes T, Conde DM, Costa-Paiva L, Pinto NAM. Epidemiologia da menopausa e dos sintomas climatéricos em mulheres de uma região metropolitana no sudeste do Brasil: inquérito populacional domiciliar. Rev Bras Ginecol Obstet. 2015; 37(4):152-8.

9. Blümel JE, Chedraui P, Baron G, Belzares E, Bencosme A, Calle A, et al. A large multinational study of vasomotor symptom prevalence, duration, and impact on quality of life in middleaged women. Menopause. 2011; 18(7):778-85.

10. Silva Filho CR, Baracat EC, Conterno LO, Haidar MA, Ferraz MB. Climacteric symptoms and quality of life: validity of women's health questionnaire. Rev Saúde Pública. 2005; 39(3):333-9.

11. Ministério da Saúde (BR). Sala de apoio à gestão estratégica (SAGE). [Internet]. 2015 [citado 2014 maio 30]. Disponível em: http://189.28.128.178/ sage/

12. Tao M, Shao H, Li C, Teng Y. Correlation between the modified Kupperman Index and the Menopause Rating Scale in Chinese women. Patient Prefer Adherence. 2013; 7:223-9. 
13. Araújo JBS, Santos GC, Nascimento MA, Dantas JGS, Ribeiro ASC. Avaliação da intensidade da sintomatologia do climatério em mulheres: Inquérito populacional na cidade de Maceió, Alagoas. Ciênc Biol Saúde. 2015; 2(3):101-11.

14. Paiva ER, Silva MM, Oliveira CDB, Leal IHS, Araújo VS, Dias MD. Manifestações climatéricas mais frequentes entre mulheres de uma unidade de saúde da família. Rev Enferm UFPE On line [Internet]. 2013 [citado $2015 \mathrm{fev} 22$ ]; 7(11):64307. Disponível em: http://www.revista.ufpe.br/ revistaenfermagem/index.php/revista/article/ view/3793/pdf_3902.

15. Silva AR, Tanaka ACA. Factors associated with menopausal symptoms severity in middle-aged Brazilian women from the Brazilian Western Amazon. Maturitas 2013; 76(1):64-9.

16. Oppermann K, Fuchs SC, Donato G, Bastos CA, Spritzer PM. Physical, psychological, and menopause-related symptoms and minor psychiatric disorders in a community-based sample of Brazilian premenopausal, perimenopausal, and postmenopausal women. Menopause. 2012; 19(3):355-60.
17. Worsley R, Bell R, Kulkarni J, Davis SR. The association between vasomotor symptoms and depression during perimenopause: a systematic review. Maturitas. 2014; 77(2):111-7.

18. Hachul H, Bittencourt LRA, Soares Jr JM, Tufik S, Baracat EC. Sleep in post-menopausal women: Differences between early and late postmenopause. Eur J Obstet Gynecol Reprod Biol. 2009; 145(1):81-4.

19. Cabral PUL, Canário ACG, Spyrides MHC, Uchôa SAC, Eleutério JJ, Amaral RLG, et al. Influência dos sintomas climatéricos sobre a função sexual de mulheres de meia-idade. Rev Bras Ginecol Obstet. 2012; 34(7): 329-34.

20. Silveira IL, Petronilo PA, Souza MO, Silva TDNC, Duarte JMBP, Maranhão TMO, et al. Prevalência de sintomas do climatério em mulheres dos meios rural e urbano no Rio Grande do Norte, Brasil. Rev Bras Ginecol Obstet. 2007; 29(8):420-7. 